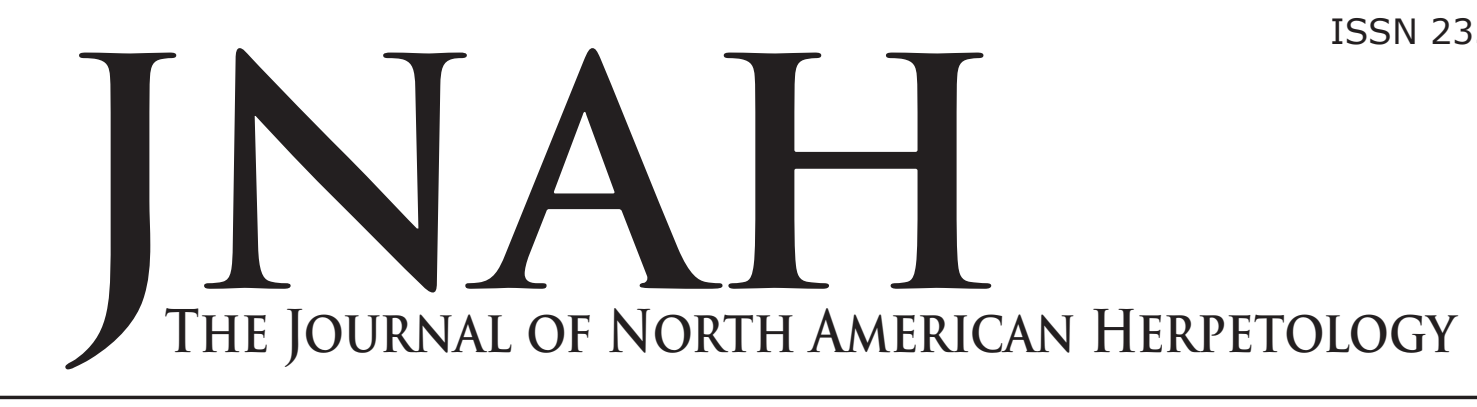

Volume 2015(1): 17-21 1 May $2015 \quad$ jnah.cnah.org

\title{
POPULATION ECOLOGY OF THE NORTHERN SLIMY SALAMANDER (PLETHODON GLUTINOSUS) IN EAST-CENTRAL ILLINOIS
}

\author{
JOHN A. CRAWFORD ${ }^{1,4}$, ANDREW R. KUHNS², AND MATHYS J. MEYER ${ }^{3}$ \\ ${ }^{1}$ National Great Rivers Research and Education Center, East Alton, IL 62024 \\ ${ }^{2}$ University of Illinois at Urbana-Champaign, Prairie Research Institute, Illinois Natural History \\ Survey, Champaign, IL 61820 \\ ${ }^{3}$ University of Pikeville, Division of Mathematics and Science, Pikeville, KY 41501 \\ ${ }^{4}$ Author for correspondence: joacrawford@lc.edu
}

\begin{abstract}
The importance of plethodontid salamanders in forested habitats has been recognized for decades and more recently plethodontids have been touted as a model taxon for monitoring ecosystem integrity and recovery. However, basic demographic data that are crucial to conservation and management plans are currently lacking for many species and regions. The objectives of our study were to characterize the population density, biomass, and capture success of a peripheral population of Plethodon glutinosus to provide a comparison for eastern populations and set a baseline for future monitoring of Midwestern populations. We estimated the population density of P. glutinosus at our site to be 0.41 salamanders $/ \mathrm{m}^{2}$, with an estimated biomass of $0.70 \mathrm{~g} / \mathrm{m}^{2}$. We did not find any evidence for temperature or precipitation affecting capture success. Our results showed that our density estimate falls within the range of other population ecology studies of Plethodon and sets a baseline for other peripheral Midwestern populations.
\end{abstract}

\section{INTRODUCTION}

The importance of plethodontid salamanders in forested habitats has been recognized for decades (Hairston, 1987; Davic and Welsh, 2004; Peterman et al., 2008). More recently, plethodontids have been used as a model taxon for monitoring ecosystem integrity and recovery (Welsh and Droege, 2001; Welsh and Hodgson, 2013) because of their unique physiology (lungless; semipermeable skin), which makes them susceptible to slight variations in their environment. Additionally, plethodontids are long-lived, highly philopatric, and exist in relatively stable populations (Hairston, 1987; Welsh and OIlivier, 1998). Despite their importance in and to forested habitats, the population ecology of many plethodontid species remains unstudied (see plethodontid species accounts in Lannoo, 2005). Further, there is a relative lack of information on the population ecology of plethodontids in the Midwestern United States, which represents the western range limit for a number of species (Lannoo, 2005). Data from these peripheral populations may be of conservation value because these populations may contain genotypic and phenotypic variation not present in the main portions of their range (Brown, 1984); however peripheral populations are expected to be smaller in size making them more prone to extirpation events (Kirkpatrick and Barton, 1997).
Because of greater plethodontid richness and abundance in the Eastern United States, studies from this region are more common than in the Midwest (e.g., Petranka and Murray, 2001; Peterman et al., 2008; Crawford and Peterman, 2013). Studies have shown that biomass estimates from the Eastern U.S. are highly variable and range from $0.18 \mathrm{~g} / \mathrm{m}^{2}$ (Burton and Likens, 1975) in the north to $27.16 \mathrm{~g} / \mathrm{m}^{2}$ in the southern Appalachian Mountains (Crawford and Peterman, 2013). Further, there can also be a great deal of variation within a single species; biomass estimates for the Black-bellied Salamander (Desmognathus quadramaculatus) range from 0.60 $\mathrm{g} / \mathrm{m}^{2}$ (Davic and Welsh, 2004) to $9.93 \mathrm{~g} / \mathrm{m}^{2}$ (Peterman et al., 2008). Variation in biomass estimates allows for inferences to be made into of the biological productivity of forested ecosystems and the relative importance that each species has within an ecosystem (Davic and Welsh, 2004). However, in certain instances, the variability of biomass estimates may be due to temporary immigration and/or to a large portion of the salamander population occurring below the surface (Bailey et al., 2004).

Plethodon glutinosus (Northern Slimy Salamander) has a broad distribution ranging from south-central Illinois to New York and south to Alabama and Georgia (Beamer and Lannoo, 2005). Throughout its range, P. glutinosus is more abundant in mature forests (Bennett et al., 1980; 
Table 1. Summary of published density and biomass estimates from salamanders in the genus Plethodon.

\begin{tabular}{llll}
\hline Species & Density (ind./m²) & Biomass $\left(\mathrm{g} / \mathrm{m}^{2}\right)$ & Reference \\
\hline P. cinereus & $0.09-0.89$ & N/A & Heatwole, 1962 \\
P. cinereus & 0.5 & N/A & Kniowski and Reichenbach, 2009 \\
P. glutinosus & 0.41 & 0.70 & Crawford et al., This study \\
P. glutinosus (= cylindraceus) & 0.004 & N/A & Gordon et al., 1962 \\
P. glutinosus & 0.23 & N/A & Merchant, 1972 \\
P. glutinosus & 0.069 & 0.275 & Petranka and Murray, 2001 \\
P. glutinosus & $0.418-0.844$ & N/A & Semlitsch, 1980 \\
P. hubrichti & $0.6-3.3$ & N/A & Kniowski and Reichenbach, 2009 \\
P. jordani & 0.18 & N/A & Ash, 1988 \\
P. jordani & 0.86 & N/A & Merchant, 1972 \\
P. jordani & 0.86 & N/A & Petranka, 1998 \\
P. kentucki & $<0.20$ & N/A & Marvin, 1996 \\
P. punctatus & $0.36-0.67$ & N/A & Flint and Harris, 2005 \\
P. punctatus & $0.03-0.54$ & N/A & Fraser, 1976 \\
P. shenandoah & 0.1 & N/A & Griffis and Jaeger, 1998 \\
P. wehrlei & 0.1 & Hall and Stafford, 1972 \\
\hline
\end{tabular}

Grant et al., 1994) and is typically found under logs and rocks (Bishop, 1941; Rubenstein, 1969). Given Highton (2005) found $87 \%(26 / 30)$ of the P. glutinosus populations he sampled had experienced declines and the apparent declines of a number of amphibian species in the Midwest (see Lannoo, 1998), it is important to investigate the population ecology of Midwestern amphibians in order to guide conservation efforts. To that end, the objectives of our study were to characterize the population density, biomass, capture success, and habitat use of a peripheral population of $\mathrm{P}$. glutinosus to provide a comparison to eastern populations and set a baseline for future monitoring of Midwestern populations.

\section{MATERIALS AND METHODS}

The site for this study was located in Kickapoo State Recreation Area, Vermilion County, Illinois, USA (40.13579, -87.74862). Our 70 x $50 \mathrm{~m}$ study plot was located on a north-facing slope in a deciduous forest that consisted primarily of sugar maple (Acer saccharum) and mixed oaks (Quercus spp.). Within the study plot, leaf litter was relatively uniform (averaging $50.5 \mathrm{~mm}$ in depth) and there was an abundance of coarse woody debris and rocks. Two species of salamanders, Plethodon cinereus (Eastern Red-backed Salamander) and P. glutinosus, were readily encountered on the plot while adult Eurycea cirrigera (Southern Two-lined Salamander) were occasionally encountered.

We conducted mark-recapture surveys approximately once every four days; twenty-nine plot searches were conducted between 31 March (first plot search) and 25 July 2001 (last plot search). The $70 \times 50$ m study plot was divided into $1 \mathrm{~m}^{2}$ grids and we searched each grid moving in a serpentine fashion through the plot. Within each grid all appropriate cover items were over-turned to search for salamanders and were subsequently replaced. When a salamander was encountered, we recorded the grid number in which it was found as well as the type of cover object it was under (coarse woody debris or rock) and the length/width of the cover object (to calculate the area of the object). Salamanders were captured and placed in a plastic bag, weighed with a Pesola ${ }^{\mathrm{TM}}$ spring scale to the nearest $0.25 \mathrm{~g}$, and measured with a plastic hand ruler to the nearest $\mathrm{mm}$ for snout-vent length (SVL) and total length (TL). Each novel salamander captured was given a unique toe clip (toe clipping has

repeatedly been found to be an acceptable and effective method of amphibian marking; Perry et al., 2011; Brantley et al. 2014). Upon recapture, each clipped toe was inspected for regrowth and the toe was reclipped if visible regrowth was apparent. We did not clip more than two digits per foot, no adjacent digits were clipped, and no salamander had more than five toes clipped during the study. All salamanders were released at the point of capture following demographic data collection. The mark-recapture data were analyzed with open population models using Jolly-Seber estimation in Program MARK (version 6.2; available from http://warnercnr.colostate. edu/ gwhite/mark/mark.htm) to provide population size estimates. The population estimate was divided by the plot size $\left(3500 \mathrm{~m}^{2}\right)$ to determine the average density/ $\mathrm{m}^{2}$ of salamanders. Biomass was calculated by multiplying the density of salamanders by the average weight of salamanders in the population. The average weight was determined using only initial capture weights of the 773 salamanders in the study.

To determine if either temperature or precipitation affected the number of salamanders captured per sampling period we used linear regressions. Specifically, we evaluated the effect of: 1) maximum temperature the day before sampling; 2) minimum temperature the day

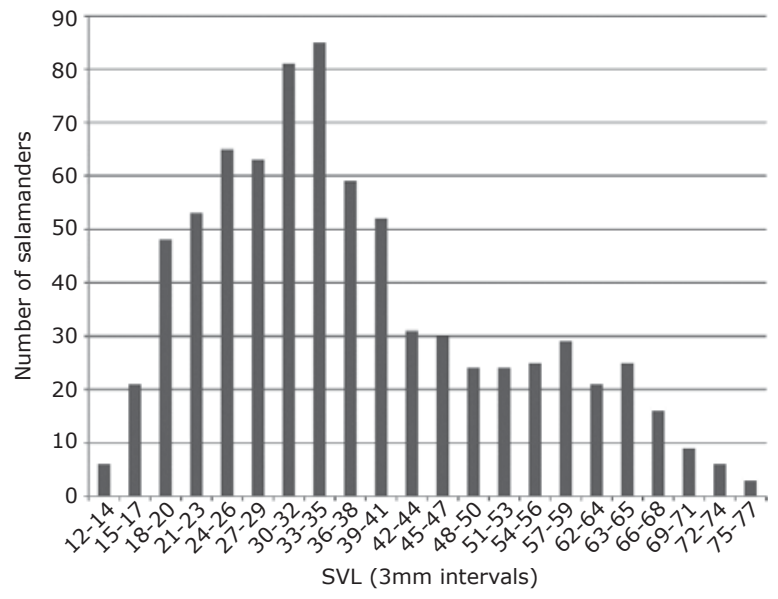

Figure 1. Size histogram of a population of Plethodon glutinosus near their western range limit, Vermilion County, Illinois. 
before sampling; 3) average temperature the day before sampling; 4) total precipitation in the 24 hours prior to sampling; and 5) total precipitation in the 120 hours before sampling. We used an independent samples t-test to determine if the size of salamanders found under coarse woody debris was significantly different $(P<0.05)$ from salamanders found under rocks (using only SVL from initial salamander capture events). Lastly, we used a linear regression to determine if the number of salamanders captured increased as the total area of a cover object increased. All statistical analyses were conducted in IBM SPSS Statistics for Windows (version 19.0).

\section{RESULTS}

We captured 773 unique $P$. glutinosus with 468 recapture events. We averaged 43 captures per survey (range = 2-96). Recapture events ranged from 1-6 with 464 salamanders that were never recaptured. The total estimated population size in the study plot $\left(3500 \mathrm{~m}^{2}\right)$ was 1433 salamanders ( $95 \% \mathrm{CI}=1115-1752)$, and the total estimated biomass was $2464.76 \mathrm{~g}$ (95\% CI $=1917.80-$ 3013.44). The estimated population density of salamanders on the study plot was 0.41 salamanders $/ \mathrm{m}^{2}$. We considered individuals $\leq 46 \mathrm{~mm}$ in SVL to be juveniles (Highton 1962) and an age structure diagram revealed that the majority of the salamanders in the population were pre-reproductive individuals (juveniles and subadults; Figure 1).

We did not find a significant relationship between number of salamanders captured per sampling period and maximum temperature $\left(F_{(1,27)}=0.758 ; P=0.392 ; R^{2}\right.$ $=0.027)$, minimum temperature $\left(F_{(1,27)}=0.809 ; \mathrm{P}=\right.$ $\left.0.376 ; R^{2}=0.029\right)$, average temperature $\left(F_{(1,27)}=0.832\right.$; $\left.\mathrm{P}=0.370 ; \mathrm{R}^{2}=0.030\right), 24$ hour precipitation $\left(\mathrm{F}_{(1,27)}=\right.$ $\left.2.827 ; \mathrm{P}=0.104 ; \mathrm{R}^{2}=0.095\right)$, or 120 hour precipitation $\left(F_{(1,27)}=1.842 ; P=0.186 ; R^{2}=0.064\right)$. Capture success was relatively constant throughout the activity season (Figure 2). There were only three sampling periods (of the 29 total) in which there were no precipitation events in the 120 hours preceding sampling.

Of the 773 unique captures, we found 565 individuals (429 juveniles, 136 adults) under coarse woody debris and 208 individuals (152 juveniles, 56 adults) under rocks. Overall there was no significant difference in SVL of individuals under the two types of cover objects $\left(\mathrm{T}_{(771)}=0.110 ; \mathrm{P}=0.913\right)$. Additionally, there was no significant difference in SVL of juveniles found under the two types of cover objects $\left(T_{(579)}=1.556 ; \mathrm{P}=0.118\right)$ or

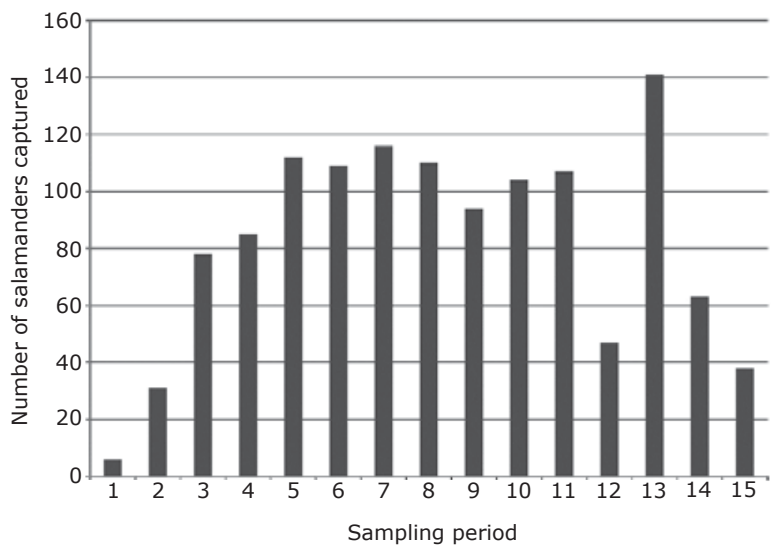

Figure 2. Capture success of Plethodon glutinosus during the study in Vermilion County, Illinois. In the figure each sampling period represents the total number of salamanders captured in two consecutive surveys. adults found under the two types of cover objects ( $T_{(190)}$ $=0.335 ; P=0.738$ ). There was a significant trend for number of salamanders to increase as the total area of a cover object increased $\left(F_{(1,697)}=201.793 ; P<0.001 ; R^{2}\right.$ $=0.225$; Figure 3).

\section{DISCUSSION}

We estimated the population density of $\mathrm{P}$. glutinosus at our site to be 0.41 salamanders $/ \mathrm{m}^{2}$, with an estimated biomass of $0.70 \mathrm{~g} / \mathrm{m}^{2}$. Thus, the population we studied falls within the range of other population ecology studies of Plethodon (Table 1). In studies of P. glutinosus, both Gordon et al. (1962) and Petranka and Murray (2001) found very low densities of these salamanders in their study plots $\left(0.004 / \mathrm{m}^{2}\right.$ and $0.069 / \mathrm{m}^{2}$, respectively; Table 1); while Merchant (1972) and Semlitsch (1980) found higher densities of $P$. glutinosus in their study plots $\left(0.23 / \mathrm{m}^{2}\right.$ and $0.418-0.844 / \mathrm{m}^{2}$, respectively; Table 1$)$. Despite our population existing near the periphery of the species range, our density estimate is average to above average when compared to the aforementioned studies. Only Petranka and Murray (2001) have provided a prior biomass estimate for $P$. glutinosus $\left(0.275 \mathrm{~g} / \mathrm{m}^{2}\right.$; Table 1 ) from an eastern population, so biomass comparisons are limited.

Due to their physiological requirements, plethodontids typically require cool, moist environments so precipitation and temperature can considerably affect the demography, activity, life history, and distribution of plethodontid populations. Milanovich et al. (2006) found that the amount of precipitation in the year prior to oviposition in P. albagula (Western Slimy Salamander) was correlated with clutch size, while Wells and Wells (1976) found that prolonged droughts can alter terrestrial activity patterns of $\mathrm{P}$. glutinosus. Further, temperature and precipitation have been shown to significantly influence abundance and capture success. Grover (1998) found that on experimental plots that received supplemental water (vs. unwatered controls), abundance of both P. cinereus and $P$. glutinosus were significantly increased. Williams and Berkson (2004) found that increased temperature decreased the probability of detection of $P$. cinereus, while recent precipitation events were positively correlated with detection probability. In this study we did not find any evidence for temperature or precipitation affecting capture success. Our relatively constant capture success may be attributed to the frequency of rain events at our site in 2001. All but three sampling events occurred within 120 hours of a precipitation event. However, the

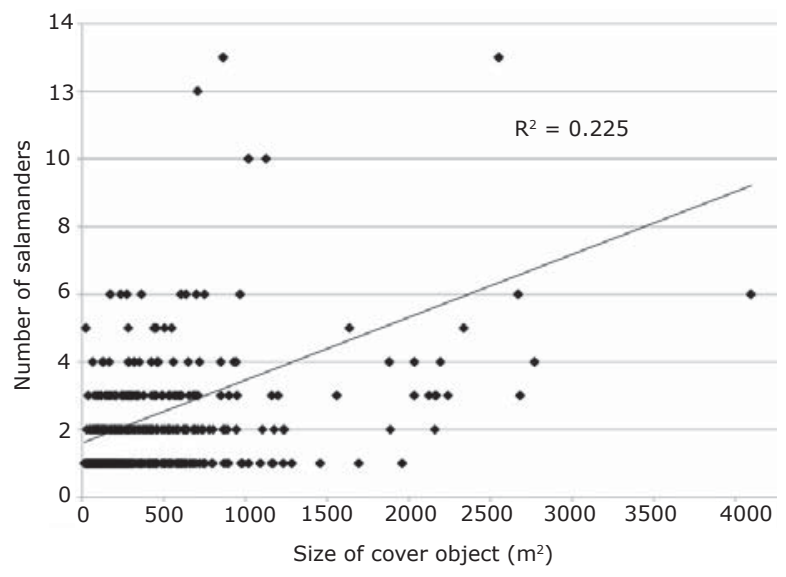

Figure 3. Effect of cover object size (total area) on number of Plethodon glutinosus captured. 
surface activity (and capture probability) of $\mathrm{P}$. glutinosus is likely less affected by temperature and precipitation as compared to smaller species of Plethodon due to their greater surface area to volume ratio. Studies on larger species of Plethodon have shown that surface activity is largely unaffected by moisture (Petranka and Murray, 2001) or time since last rainfall event (Kniowski and Reichenbach, 2009).

In contrast to other studies investigating microhabitat use of Plethodon, we found no significant differences in microhabitat use (rocks vs. coarse woody debris) of adults and juveniles. Kniowski and Reichenbach (2009) found that adult and juvenile cohorts of both $P$. cinereus and P. hubrichti significantly preferred rocks to leaf litter and logs. However, our results may have been influenced by the consistent precipitation throughout the sampling period and preferences may become apparent during drier periods. We did find a trend for an increase in capture number of P. glutinosus as the cover object size increased (Figure 3 ). This also seems to differ from more eastern populations of $P$. glutinosus where it is unusual to capture multiple salamanders under one cover object, regardless of cover object size (Wells and Wells, 1976).

The long-term persistence of many wildlife populations is in doubt due to anthropogenic factors such as habitat loss and climate change, with the greatest risk to peripheral populations; thus monitoring of these populations can be crucial in detecting early ecosystem changes. Additionally, the lack of basic demographic data for most species limits the effectiveness of conservation and management strategies (Mills, 2013). In this study we have provided basic demographic data on a broadly distributed species (in a peripheral location) to be used in comparison with other populations throughout the range of P. glutinosus. While future research will continue in the conservation and management of wildlife populations, we urge others to undertake basic demographic studies to collect this valuable data and implore scholarly outlets to publish this valuable information so that conservation and land managers will have it available to make land use decisions.

\section{ACKNOWLEDGMENTS}

We thank the staff at Kickapoo State Recreation Area for granting us access to the study site and approving the study design. We also thank G. Homrighaus for field assistance. This research was conducted under Illinois Department of Natural Resources permit \#A01.0205 and animal care methods followed protocols from Guidelines for Use of Live Amphibians and Reptiles in Field Research compiled by ASIH, HL, and SSAR (document can be accessed at: http://www.aaalac.org/accreditation/Guidelines_for_Use_of_Live_Amphibians_and_Reptiles.pdf).

\section{LITERATURE CITED}

Ash, A. 1988. Disappearance of salamanders from clearcut plots. Journal of the Elisha Mitchell Scientific Society 104:116-122.

Bailey, L.L., T.R. Simons, and K.H. Pollock. 2004. Comparing population sizeestimators for plethodontid salamanders. Journal of Herpetology 38:370-380.

Beamer, D.A., and M.J. Lannoo. 2005. Plethodon glutinosus species account. Pp. 808-811 In Amphibian Declines: The Conservation Status of United States Species, M.J. Lannoo (Ed.), University of California Press, Berkeley, California.

Bennett, S.H., J.W. Gibbons, and J. Glanville. 1980. Terrestrial activity, abundance, and diversity of am- phibians in differently managed forest types. American Midland Naturalist 103:412-416.

Bishop, S.C. 1941. The Salamanders of New York. New York State Museum Bulletin, Number 324, Albany, New York.

Brantley, L.A., L. Berger, and L.F. Skerratt. 2014. Comparison of three widely used marking techniques for adult anuran species Litoria verreauxii alpina. Herpetological Conservation and Biology 9:428-435.

Brown, J.H. 1984. On the relationship between abundance and distribution of species. The American Naturalist 124:255-279.

Burton, T.M., and G.E. Likens. 1975. Salamander populations and biomass in the Hubbard Brook Experimental Forest, New Hampshire. Copeia 1975:541546.

Crawford, J.A., and W.E. Peterman. 2013. Biomass and habitat partitioning of Desmognathus on wet rock faces in the southern Appalachian Mountains. Journal of Herpetology 47:580-584.

Davic, R.D., and H.H. Welsh Jr. 2004. On the ecological roles of salamanders. Annual Review of Ecology, Evolution, and Systematics 35:405-434.

Flint, W.D., and R.N. Harris. 2005. The efficacy of visual encounter surveys for population monitoring of Plethodon punctatus (Caudata: Plethodontidae). Journal of Herpetology 39:578-584.

Fraser, D.F. 1976. Coexistence of salamanders in the genus Plethodon: a variation of the Santa Rosalia theme. Ecology 57:238-251.

Gordon, R.E., J.A. MacMahon, and D.B. Wake. 1962. Relative abundance, microhabitat and behavior of some southern Appalachian salamanders. Zoologica 47:9-14.

Grant, B.W., K.L. Brown, G.W. Ferguson, and J.W. Gibbons. 1994. Changes in amphibian biodiversity associated with 25 years of pine forest regeneration: implications for biodiversity management. Pp. 354367. In Biological Diversity: Problems and Challenges, S.K. Majumdar, F.J. Brenner, J.E. Lovich, J.F. Shalles, and E.W. Miller (Eds.), Pennsylvania Academy of Science, Easton, Pennsylvania.

Griffis, M.R., and R.G. Jaeger. 1998. Competition leads to an extinction-prone species of salamander: interspecific territoriality in a metapopulation. Ecology 79:2494-2502.

Grover, M.C. 1998. Influence of cover and moisture on abundance of the terrestrial salamanders Plethodon cinereus and Plethodon glutinosus. Journal of Herpetology 32:489-497.

Hairston, N.G. 1987. Community Ecology and Salamander Guilds. Cambridge University Press, U.K.

Hall, R.J., and D.P. Stafford. 1972. Studies in the life history of Wehrle's salamander, Plethodon wehrlei. Herpetologica 28:300-309.

Heatwole, H. 1962. Environmental factors influencing local distribution and activity of the salamander Plethodon cinereus. Ecology 43:460-472.

Highton, R. 1962. Geographic variation in the life history of the slimy salamander. Copeia 1962:597-613.

Highton, R. 2005. Declines of eastern North American woodland salamanders (Plethodon). Pp. 34-46. In Amphibian Declines: The Conservation Status of United States Species, M.J. Lannoo (Ed.), University of California Press, Berkeley, California.

Kirkpatrick, M., and N.H. Barton. 1997. Evolution of a species' range. The American Naturalist 150:1-23.

Kniowski, A., and N. Reichenbach. 2009. The ecology of 
the Peaks Otter salamander (Plethodon hubrichti) in sympatry with the eastern red-backed salamander (Plethodon cinereus). Herpetological Conservation and Biology 4:285-294.

Lannoo, M.J. 1998. Status and Conservation of Midwestern Amphibians. University of Iowa Press, Iowa City, Iowa.

Lannoo, M.J. 2005. Amphibian Declines: The Conservation Status of United States

Species. University of California Press, Berkeley, California.

Marvin, G.A. 1996. Life history and population characteristics of the salamander Plethodon kentucki with a review of Plethodon life histories. American Midland Naturalist 136:385-400.

Merchant, H.C. 1972. Estimated population size and home range of the salamanders Plethodon jordani and Plethodon glutinosus. Journal of the Washington Academy of Sciences 62:248-257.

Milanovich, J.R., S.E. Trauth, D.A. Saugey, and R.R. Jordan. 2006. Fecundity, reproductive ecology, and influence of precipitation on clutch size in the western slimy salamander (Plethodon albagula). Herpetologica 62:292-301.

Mills, L.S. 2013. Conservation of Wildlife Populations: Demography, Genetics, and Management. WileyBlackwell Press, Hoboken, New Jersey.

Perry, G., M.C. Wallace, D. Perry, H. Curzer, and P. Muhlberger. 2011. Toe clipping of amphibians and reptiles: Science, ethics, and the law. Journal of Herpetology 45:547-555.

Peterman, W.E., J.A. Crawford, and R.D. Semlitsch. 2008. Productivity and significance of headwater streams: population structure and biomass of the Black-bellied Salamander (Desmognathus quadramacula- tus). Freshwater Biology 53:347-357.

Petranka, J.W. 1998. Salamanders of the United States and Canada. Smithsonian Institution Press, Washington, D.C.

Petranka, J.W., and S.S. Murray. 2001. Effectiveness of removal sampling for determining salamander density and biomass: a case study in an Appalachian streamside community. Journal of Herpetology 35:36-44.

Rubenstein, N.M. 1969. A study of the salamanders of Mount Cheaha, Cleburne County, Alabama. Journal of Herpetology 3:33-47.

Semlitsch, R.D. 1980. Geographic and local variation in population parameters of the slimy salamander Plethodon glutinosus. Herpetologica 36:6-16.

Wells, K.D., and R.A. Wells. 1976. Patterns of movement in a population of the slimy salamander, Plethodon glutinosus, with observations of aggregations. Herpetologica 32:156-162.

Welsh Jr., H.H., and L.M. Ollivier. 1998. Stream amphibians as indicators of ecosystem stress: a case study from California's redwoods. Ecological Applications 8:1118-1132.

Welsh Jr., H.H., and S. Droege. 2001. A case for using plethodontid salamanders for monitoring biodiversity and ecosystem integrity of North American forests. Conservation Biology 15:558-569.

Welsh Jr., H.H., and G.R. Hodgson. 2013. Woodland salamanders as metrics of forest ecosystem recovery: a case study from California's redwoods. Ecosphere 4:59.

Williams, A.K., and J. Berkson. 2004. Reducing false absences in survey data: Detection probabilities of red-backed salamanders. Journal of Wildlife Management 68:418-428. 